Amaltea. Revista de mitocrítica

ISSN-e: 1989-1709

http://dx.doi.org/10.5209/amal.62319

\title{
La Odisea en la casilla de salida del Juego de la Oca
}

\author{
Javier Almódovar García ${ }^{1}$; José Ramón del Canto Nieto²
}

Resumen. La huella que ha dejado en el imaginario occidental la Odisea resulta inagotable. De ella se sigue una tradición literaria, pero también icónica. En el artículo se rastrea el origen de los "juegos de mesa" en la Antigüedad grecorromana y su procedencia mítica; se analiza su estructura y componentes simbólicos para acabar estableciendo una relación entre la Odisea y el Juego de la Oca. Se utiliza como método, principalmente, el análisis de las funciones del cuento popular propugnada por V. Propp.

Palabras clave: Odisea; juegos de mesa; oca; laberinto; héroe; viaje; Propp.

\section{[en] The Odissey in the Start Place of the Juego de la Oca}

Abstract. The trace left by the Odissey in the Western imaginary is inexhaustible. It follows a literary but also iconic tradition. In this article we track down the origin of the "board games" in Greco-Roman Antiquity and their mythical source; its structure and symbolic components are analyzed in order to establish a relationship between the Odyssey and the Juego de la Oca. The method used for this purpose is V. Propp's analysis of the functions of the popular fairy tale.

Keywords: Board games; goose; maze; hero; travel; Propp.

Sumario. 1. Introducción. 2. Origen del Juego de la Oca. 3. El inventor mítico. 4. Elementos arquetípicos. 4.1. La oca. 4.2. El laberinto. 4.3. Las casillas, los números y los cuentos. 5. El cuento en el Juego de la Oca. 6. Conclusión. 7. Obras citadas

Cómo citar: Almódovar García, J.; Canto Nieto, J.R. del. La Odisea en la casilla de salida del Juego de la Oca. Amaltea. Revista de mitocrítica 11, 2019, 87-100

\section{Introducción}

En la escena primera del acto segundo de la obra El avaro de Molière su protagonista, Harpagón, hace una referencia al Juego de la Oca, del que se dice que ha sido renouvelé des Grecs, "remozado desde los griegos". Este marbete puede encontrarse una vez y otra en los títulos que acompañan a los tableros del juego en la Francia de los siglos XVII y XVIII ${ }^{3}$, época en que gozó de gran popularidad en el país galo. La palabra renouvellé pertenece a un amplio campo semántico: el famoso diccionario de Littré entiende Rendu nouveau, sugiriendo por ello una "reforma" o una "renovación” que, por lo demás, podría ser tanto física como espiritual: Madame de Sévigné, por ejemplo, se complace en decir a su hija: "hacía tiempo que estabais destrozada,

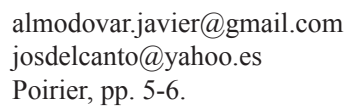


por lo que estaba triste, pero el Juego de la Oca os ha renovado del mismo modo que ese juego ha sido remozado por los griegos"4. El constante hincapié que se hace en esta idea sugiere claramente que se percibía un origen helénico del juego. Quizá se trate tan sólo de un lugar común por mor del prestigio que pudiera otorgar al juego un origen de este tipo, pero podría responder también a una intuición exacta y certera. Para reafirmar esta última tesis nos moveremos, no tanto en las vicisitudes detalladas de la evolución histórica del juego, sino más bien en los elementos estructurales y simbólicos que en sí encierra y que revelan, creemos, una deuda con el genio griego y, más en concreto, con el imaginario de Homero.

\section{Origen del Juego de la Oca}

El filósofo alemán Cassirer ${ }^{5}$, en su búsqueda de una visión global de la cultura humana, ha demostrado que la característica primordial y constitutiva del hombre es su condición simbólica. Toda la realidad se halla trabada en la urdimbre que posibilitan el espacio y el tiempo; a diferencia de los animales, el hombre puede enfrentarse a ellos no de forma directa e inmediata, sino también de una manera simbólica. Siguiendo esta misma senda, Huizinga ha explicado una dimensión que pertenece al homo symbolicus, la que lo constituye como homo ludens. A diferencia de los animales, que también juegan, cuando observamos al hombre, enseguida comprendemos que "el juego, en cuanto tal, traspasa los límites de la ocupación puramente biológica o física", porque, "en el juego, entra en juego algo que rebasa el instinto inmediato de conservación que da un sentido a la ocupación vital. Todo juego significa algo"6. Características propias del juego son para el autor la separación de la vida corriente por obra de un peculiar lugar y duración, que gozan entonces de un orden "propio y absoluto"7; característica esencial es también el hecho de actuar como si en referencia a la realidad. El juego contiene, de una manera esencial, la fragmentación propia del simbolismo: es, en efecto, un sistema privilegiado que habita en formas espaciales y temporales propias, pero, al mismo tiempo, puede referirse a la vida real (o imaginaria) haciendo posible así encarnar y conjugar algunas de las más profundas experiencias y arquetipos del mundo real (o imaginario). En tal sentido, puede considerarse una imago mundi: "el juego es una lucha por algo o una representación de algo. Ambas funciones pueden fundirse de suerte que el juego represente una pugna por ver quién reproduce mejor algo", concluye Huizinga. El imaginario en que se asienta el Juego de la Oca es, según consideramos, además de la vida real, el imaginario que ofrece la Odisea.

Si nos atenemos a la historia en sentido estricto, el primer dato contrastado de la existencia del Juego de la Oca del que se tiene noticia es de 1597: se trata del registro en The Stationer's Company Register de Londres de un juego llamado The royal and most pleasant game of the goose. Más inequívoca resulta la referencia de Pietro Carrera en 1617, según el cual, el juego se inventó en Florencia y, como gustó mucho a

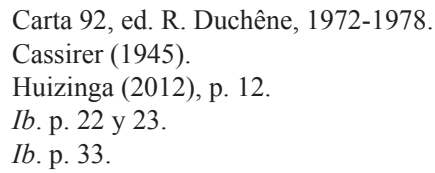


Francisco de Médici, se lo mandó como regalo al rey Felipe II de España9. Pero, siguiendo nuestro método, podemos remontarnos a un sustrato anterior, a sus orígenes míticos.

El elemento espacio-temporal en el que se desarrolla el Juego de la Oca es el tablero y, en este sentido, se engloba en la más amplia denominación de "juegos de mesa". En lo que se refiere al origen de los juegos en general, ya Heródoto aportaba datos significativos: para él fueron los lidios quienes, en tiempos del rey Atis, inventaron los juegos de mesa cuando una carestía inmensa asolaba al país y para afrontarla idearon la siguiente treta: establecieron que de cada dos días uno habrían de pasarlo sin probar bocado y jugando, para así engañar al hambre. Fue de esta manera cómo los lidios inventaron el juego de dados, los astrálagos, la pelota y otros muchos, excepto, señala de manera significativa Heródoto, un juego especial: los péssoi $(\pi \lambda \dot{\eta} v \pi \varepsilon \sigma \sigma \tilde{\omega} v)^{10}$. Suelen considerarse péssoi, también llamados petteia en la Antigüedad, a los "juegos de mesa" o "de tablero" en general. El origen de la palabra es oscuro $^{11}$. A partir de algunas referencias literarias, podemos deducir que se trataba de un juego en que unas piezas $(\lambda i \theta o l, \psi \tilde{\eta} \varphi \circ \imath)$ eran movidas a través de un tablero; como veremos, en esta sencilla acción hay que considerar distintas variantes. Pero, volvamos al mito.

\section{El inventor mítico}

En la construcción de la historia de la literatura intervienen diversos protagonistas. Por supuesto, el autor es personaje principal; junto a él cobran singular importancia los lectores y, cómo no, los críticos e historiadores. De todos ellos surge una creación colectiva que, en ocasiones, va más allá de la obra literaria. Esto de ningún modo quiere decir que supere a la obra original, pero de alguna manera cobra vida y perdura en el tiempo.

El ciclo troyano relata acontecimientos impregnados de dolor con actos de valentía y cobardía y no pocos de compasión. Y entre tanto hecho de guerra hubo momentos de necesidad, de hastío y también de aburrimiento.

Pero en la tradición mítica griega nada está escrito definitivamente. Autores de todas las épocas han versionado y modificado narraciones para alcanzar un mejor destino literario. Esto hace posible que junto al Odiseo del valor humano y el arrojo conviva otro Odiseo más astuto y torticero, capaz de engañar a jóvenes y ancianos, $\mathrm{o}$ de provocar la muerte de un compañero con tal de conseguir lo deseado. La tradición del héroe Palamedes no tiene la importancia literaria de la de Odiseo; y, sin embargo, ambos personajes permanecen ligados por una suerte de maldición provocada por la actitud y los hechos de ambos héroes de astuta inteligencia $(\mu \tilde{\eta} \tau \imath \varsigma)$.

9 Se ha señalado como el antecedente remoto del Juego de la Oca, el Mehen o Juego de la serpiente (cf. Martínez de Parga, pp. 329-357). Hay quien ha supuesto que el juego se halla ya en el Disco de Festo que, en realidad, presenta un sistema "silábico" de escritura (cf. Ruipérez y Melena, esp. pp. 26-29). Sobre el Juego de la Oca, sus imágenes, símbolos, interpretaciones y dimensión histórica, véase el excelente libro en tantos aspectos de Martínez de Parga, esp. pp. 275-283.

10 Heródoto, 1.94,1-7.

11 Para H. Frisk, (Griechisches Etymologisches Wörtenbuch, Heidelberg 1954-1972) se trata de una piedra oblonga u ovalada para juegos de mesa; su origen quizá sea semítico (arameo, pis(s)a, según Lewy Fremdw, ad. loc). Sobre los tableros de juego en la Antigüedad, véase Pauly-Wissowa, s.u. Lusoria tabula. 
Si jugáramos un poco con esta tradición liberal del mito griego, podríamos difuminar los contornos del relato y alcanzar un objetivo que no es descabellado: enlazar el destino de Odiseo tras la guerra de Troya y las vicisitudes de su regreso a Ítaca con el Juego de la Oca, un juego simbólico que, entre otras cosas, representa los peligros y fortunas de la existencia antes del retorno al seno materno. Vayamos poco a poco con esta posibilidad leve de modificar el mito empezando por la más remota referencia.

Según la mitología griega, el primer inventor de este tipo de juegos fue Palamedes. En efecto, a este héroe se le atribuyeron desde muy pronto inventos que servían para organizar la sociedad facilitando y mejorando las condiciones de vida de la comunidad; es un héroe civilizador. El sofista Gorgias ${ }^{12}$ dice que el héroe inventó la estrategia, las letras, los pesos y medidas; y también los "péssoi como un agradable entretenimiento del ocio" ( $\pi \varepsilon \sigma \sigma o v ́ \varsigma \tau \varepsilon \sigma \chi 0 \lambda \tilde{\eta} \varsigma \not \ddot{\alpha} \lambda v \pi o v \delta \imath \iota \tau \rho \imath \beta \dot{\eta} v)$. Asimismo, para Sófocles ${ }^{13}$ el origen de la pettia ha de atribuirse a Palamedes, quien lo habría imaginado en último término como un remedio contra el tedio.

¿No puso fin acaso este al hambre de aquellos -y dicho sea con respeto a la divinidad-, no les descubrió, cuando estaban acampados tras la fatiga del oleaje, los más

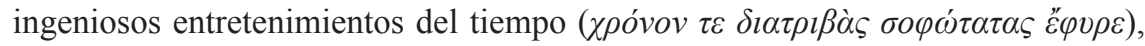

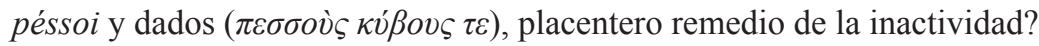

Podemos seguir leyendo en un escolio a Eurípides ${ }^{14}$ la paternidad de Palamedes acompañada de una explicación acerca de la finalidad del juego de dados, donde el hecho de "engañar el tiempo" tiene un sentido práctico:

Pasando hambre en Áulide y soportando calamidades [...] Y después hizo que en-

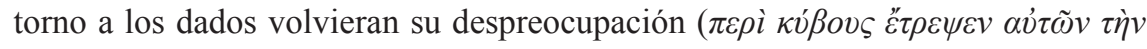
ỏ $\imath \gamma \omega \rho i \alpha v \ldots)[\ldots]$ de tal forma que adquirió gran renombre entre los griegos.

No resulta superfluo señalar que la inteligencia de Palamedes causó la envidia de Agamenón, Odiseo ${ }^{15}$ y Diomedes; una pasión malsana que desembocó en una calumnia y, en último término, en la muerte del filántropo héroe.

Parece evidente que el juego que, según la tradición, habría inventado Palamedes en Troya tuvo un rápido despliegue, si nos paramos a considerar ya en la Odisea el modo en que gastaban el tiempo los pretendientes:

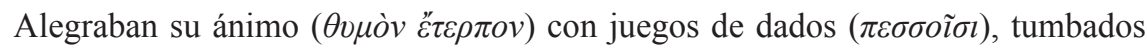
ante el portón sobre pieles de bueyes, que habían matado ellos mismos ${ }^{16}$.

Esta escena ha sido considerada ${ }^{17}$ como un ejemplo de la "mala aristocracia" por el tipo de juego al que se entregaban, opuesto a los que practicaban habitualmente los

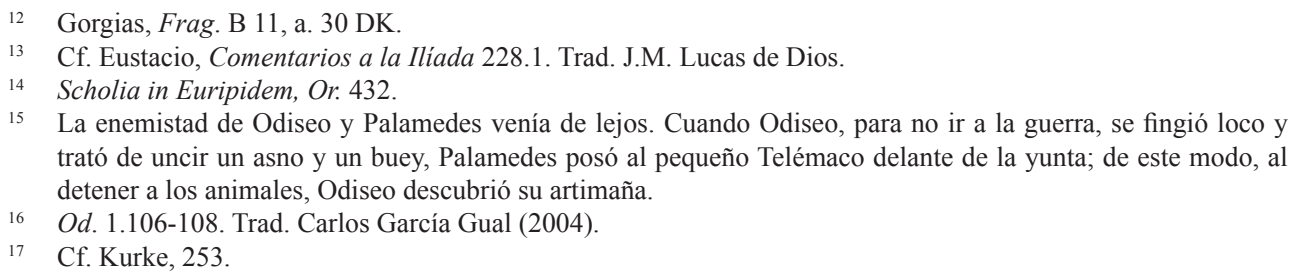


nobles, quienes solían solazarse en el ejercicio de la fuerza corporal mediante el boxeo o el tiro con arco. Los péssoi, desde esta perspectiva, vendrían a simbolizar la debilidad y la molicie.

Y, lo que es peor, era la manifestación de una violación de la hospitalidad ( $\xi \varepsilon v i ́ \alpha)$, como muestra una tradición tardía, recogida por Ateneo en su Banquete: los ciento ocho pretendientes, divididos en dos bandos, divertían su espera con un juego de mesa que consistía en empujar con fichas a la llamada "Penélope" 18.

Hay noticias de la petteia también en época arcaica; Heráclito de Éfeso, hace esta alusión:

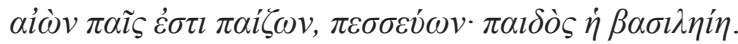

El tiempo-todo es un niño jugando, que juega al castro (o tres-en-raya): ¡castrohecho-y-derecho para el niño! (o ¡de un niño la corona!). ${ }^{19}$

En el comentario García Calvo delimita y explica el concepto del juego al que hace referencia, algo imprescindible para el entendimiento del concepto de aíóv al que simboliza:

"Un juego de posiciones relativas", lo que en la clasificación de Murray de los juegos de mesa ocupa un lugar dentro de los llamados de alineament and configuration. Había dos variantes bien conocidas: una es la que nosotros conocemos por tres-en-raya o "castro-hecho-y-derecho". Es la llamada, entre los griegos, pente grammai: "un juego en que las dos clases de fichas de color contrario luchan por ocupar sobre el sistema de líneas una disposición que las adversarias tratan continuamente de impedir; el logro de esa disposición por las unas o las otras es el final del juego".

La victoria proclama la realeza del niño $(\beta \alpha \sigma l \lambda \eta \dot{\eta})$. Entre los romanos esta variante de la petteia recibía el nombre de latrunculi ${ }^{20} \mathrm{o}$ "bandoleritos"; el ganador se proclamaba imperator. Ahora bien, sigue en su comentario García Calvo:

El tres-en-raya, con cualesquiera de sus complicaciones y hasta el ajedrez mismo, no es ciertamente un juego de veras infinito, en cuanto que, siendo número determinado los lugares, las fichas y reglas convenidas, cabe decir con buen sentido que todas las jugadas, sucesiones de jugadas y partidas enteras, están previstas en el sistema o aparato, que todo lo que se juegue estaba ya jugado.

Según el lexicógrafo Pólux ${ }^{21}$ existía otra variedad. Se jugaba con fichas situadas

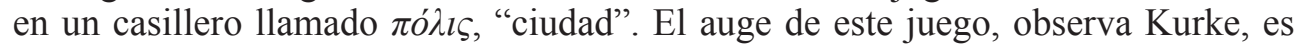
coetáneo a la aparición de la democracia ateniense (esto explicaría el empeño de Heródoto de señalar la petteia como un juego no bárbaro, sino esencialmente griego, que simbolizaría el "orden en la ciudad"). De la misma manera que en una guerra, en la disposición de los soldados en formación (la sintaxis, el llamado modernamente

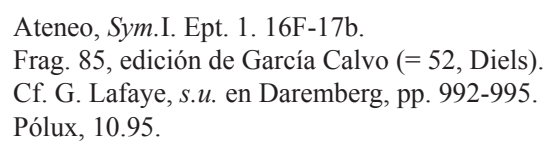


"orden cerrado"), cada miembro es esencial para el éxito de la empresa, así también cada pieza de la petteia lo es para el sistema del juego. Esto explica que Aristóteles tome el juego como ejemplo de convivencia: en la ciudad, cada ciudadano tiene su función en el sistema de la comunidad. Los que no cumplen las normas, por ello, son como una pieza suelta en un juego de damas ${ }^{22}$.

Entre los juegos de mesa en la Antigüedad pueden considerarse distintas modalidades: los de estrategia y enfrentamiento; y los de suerte y azar. Recordemos que ya Sófocles hablaba a la par de $\pi \varepsilon \sigma \sigma o v ́ \varsigma \tau \varepsilon \kappa v ́ \beta o v \varsigma$. Lo que más nos interesa ahora es constatar que dentro de esta última modalidad puede vislumbrarse una variedad que es combinación de una carrera acompañada de dados ${ }^{23}$. En esta estructura podemos suponer elementos parecidos al Juego de la Oca. Por ejemplo, en una conocida ánfora de Exequias ${ }^{24}$, dos figuras sentadas frente a frente, de quienes se nos dice que son Áyax y Aquiles, juegan sobre un tablero. Uno dice $\tau \rho \varepsilon \tilde{\imath} \varsigma$ (tres) y el otro responde $\tau \varepsilon ́ \sigma \sigma \alpha \rho \alpha$ (cuatro); puede verse cómo mueven sendas fichas. Esta representación sugiere un juego que combina dados y, seguramente, una carrera; esta sería la mayor aproximación que podemos suponer a una atribución griega estructural al Juego de la Oca.

Por su parte, la carrera puede estar mediatizada solo por el azar de los dados o también por la intervención del jugador. El juego del parchís, por ejemplo, puede definirse como un juego de azar, pero no de puro azar, porque el jugador puede decidir la ficha que mueve, la barrera que forma, etc. También en el mundo homérico el azar está en mano de los dioses, y por encima de los dioses, el Destino. Pero también se dice que los hombres son responsables de sus actos. El carácter, pues, es en cierta manera, como decía Heráclito, destino. Pues bien, ésta es una diferencia notable con el Juego de la Oca, donde todo, absolutamente todo, es producto del azar. Podemos deducir, pues, que las trazas esenciales de un juego de mesa en el que se combinaban casillas y dados, con un componente absoluto de azar, estaba ya constituido en la época clásica del mundo griego, aunque no dispongamos de más precisiones.

\section{Elementos arquetípicos}

\subsection{La oca}

Ahora bien, si consideramos los que podemos llamar elementos arquetípicos del Juego de la Oca, quizá obtengamos una visión más fructífera. Ha de constar, en primer lugar, el animal que da nombre al juego. La oca era un ave bien conocida; se sabía que frecuentaba las orillas de los ríos y lagos y que gustaba de alimentarse de los cultivos ${ }^{25}$; que migraba en formación de cuña en invierno ${ }^{26}$; Aristóteles conoce varias especies y detalla algunos aspectos de su reproducción ${ }^{27}$. En la Odisea se presenta como ave domesticada ${ }^{28}, \chi \eta v o \beta o \sigma \kappa o ́ \varsigma^{29}$; incluso Penélope tiene su propio

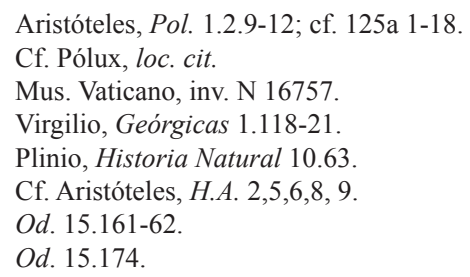


rebaño ${ }^{30}$. El peripatético Lácides describe el ave como mascota ${ }^{31}$; en las fábulas aparece, también, en su doble aspecto de ave silvestre y familiar ${ }^{32}$. Sin embargo, en

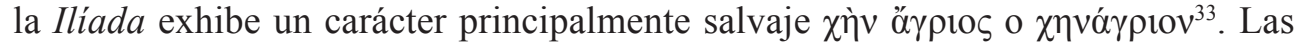
ocas, pues, podrían considerarse como figuras de mediación entre la naturaleza y la cultura. Además, se asocian simbólicamente, a través de la migración de los gansos silvestres en el otoño, al ciclo anual de la vida en la naturaleza. Todos estos aspectos resultan muy apropiados para un juego cuya acción transcurre por varios elementos. También está asociada al efecto siempre beneficioso de las madres, protagonizado por unas aves que juegan un papel propiciador fundamental en su desarrollo.

En el mito la oca aparece en la seducción de Némesis por Zeus, en un episodio de persecución y metamorfosis que cuenta Ateneo:

\begin{abstract}
A Helena la había engendrado en tiempos Némesis, la de hermosa cabellera, unida en amor a Zeus, rey de los dioses, bajo violenta coacción. En efecto, huía y no quería unirse en amor al padre Zeus Cronión, pues angustiaba su mente por el pudor y la indignación. Por tierra y por las oscuras aguas infecundas huía, mas Zeus la perseguía y ansiaba en su ánimo alcanzarla. Ella, tomando unas veces la forma de un pez entre el oleaje del mar muy bramador, perturbaba el ponto un largo trecho. Otras veces, por la corriente del Océano y los confines de la tierra, otras veces por la tierra firme, pródiga en labrantíos, se convertía continuamente en cuantas terribles criaturas sustenta la tierra firme para eludirlo ${ }^{34}$.
\end{abstract}

Finalmente, Némesis se convirtió en oca pero Zeus, convertido a su vez en cisne, se unió a ella.

La oca, asociada con juegos, gozó de ricas figuraciones en la Antigüedad. En un mosaico romano de Cartago se representa un carro de dos ruedas tirado por dos ocas blancas con nuca gris y alas rojas ${ }^{35}$. En la marroquí Volúbilis, en la Casa de Venus se ha encontrado un mosaico que representa la spina de un circo en miniatura alrededor del cual corren carros tirados por ocas y conducidos por aurigas de distintos colores. En los baños romanos de la ciudad argelina de Tébassa puede verse una pieza llamada "mosaico de los juegos" o "Fortuna Redux". La mitad del pavimento está cubierta por una guirnalda de laurel, signo de la victoria; están representadas unas casillas de distintos animales con una numeración adjunta: un jabalí con el número VIII, una gacela con el II, un avestruz con la inscripción CURI[S], un toro con el número X y un oso con el XVIII; la oca se encuentra en postura de saltar en el aire ${ }^{36}$.

\title{
4.2. El laberinto
}

En su forma, el tablero del Juego de la Oca compone una espiral involutiva dividida en 63 casillas. En sus círculos concéntricos representa un laberinto que, de hecho, aparece en la casilla 42. El objetivo final del juego, que no es sino un viaje como el

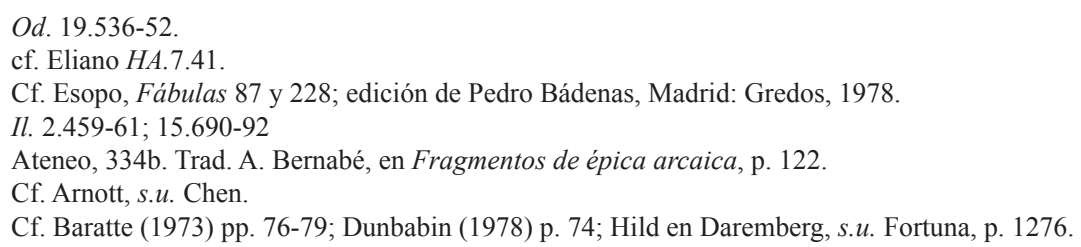


de Odiseo, es volver al principio, al origen. Seguramente esta es la razón por la que la espiral involutiva, que guarda un simbolismo siniestro y destructivo, carece de este carácter en el juego, al reunir final y principio; su desenlace no es la destrucción, sino la gloria ${ }^{37}$.

Una categoría dentro de la clasificación de los laberintos es la de los unidireccionales, en los que ha de recorrerse un solo camino de manera lineal, aunque también puede ser en espiral. Cuenta Apolodoro que cuando Minos perseguía a Dédalo, conocedor de su perspicacia, llevaba consigo una caracola y ofrecía una gran recompensa a quien consiguiera enhebrar un hilo a través de ella. Al llegar a Sicilia, Cócalo, que había protegido a Dédalo, le mostró la caracola, y este ató un hilo a una hormiga para que atravesara la espiral interior. Así lo descubrió Minos. Este es un buen ejemplo de un laberinto unidireccional; distinto del que diseñó Dédalo en Creta, "un recinto de complicados ambages que confundían la salida" 38 . A pesar de la forma en espiral, el laberinto del Juego de la Oca es más parecido al que moraba el Minotauro. En efecto, dentro de las clasificaciones tradicionales, el del juego habría que englobarlo en el tipo de "laberinto multidireccional". Se trata de un camino al centro que alberga un peligro, como en el caso del Minotauro; pero que también puede albergar, como el Juego de la Oca, el paraíso y la salvación. El camino, en efecto, está lleno de peligros y obstáculos que el jugador ha de sortear y que lo pueden desviar de su ruta. De esta manera el juego relata una historia, un voyage traqué [viaje-trampa $]^{39}$ que va dictando el azar, impidiendo de este modo, un recorrido unilineal. En palabras de Santarcangeli, "una peregrinación impedida", una "progresión per accidentia no gobernada por otra fuerza que no sea el ciego capricho de los dados" $"$. En su trayecto, el jugador (que en primera persona sustituye a cualquier héroe) ha de sufrir pruebas para acceder al final a un lugar identificado muchas veces con el paraíso perdido. Se convierte así en metáfora del caminante o peregrino ${ }^{41}$, en cuyo recorrido pueden sumarse pruebas de purificación y expiación acordes con las funciones del cuento popular.

\subsection{Las casillas, los números y los cuentos}

Es asombrosa la perfección narrativa que podemos apreciar en la Odisea. Parece contener in nuce casi la totalidad de los cuentos. El argumento de la Odisea está articulado por relatos que conservan gran parte de la estructura de los cuentos populares. Estas narraciones se integran en la Odisea como secuencias del poema, al modo de las casillas que conforman el tablero de juego. Algunas alcanzan un desarrollo independiente (Idotea); otras se integran como secuencias en el conjunto del poema (Polifemo, Nausícaa, Calipso); y muchas se introducen parcialmente y formando parte de otra secuencia mayor (Lotófagos, Eolo, Lestrígones, Eumeo). Todas ellas influyen en el transcurso de la acción principal que llevará al héroe desde la casilla de salida, situada en Troya, hasta el desenlace final en Ítaca.

Es cierto que el argumento épico racionaliza y anula, en cierta medida, el elemento maravilloso que existía en los cuentos originales, pero con todo, podemos rastrear en

\footnotetext{
37 Sobre el tema del laberinto véase Attali (1966); Santarcangeli (1997); Méndez (2009); Ibáñez (2010).

38 Apolodoro, BM 3.3. Trad. de Margarita Rodríguez de Sepúlveda (1985).

39 En expresión de Forest Philippe, Textes et labyrinthes, citado por Atalli, p. 191.

$40 \quad$ Santarcangeli, p. 302.

41 Sobre la vinculación del Juego de la Oca con el camino de Santiago véase López Poza (2004).
} 
ellos las esencias de las narraciones que analizó desde un punto de vista estructuralista Vladimir Propp. Hasta su estudio, los cuentos solían clasificarse según el tema que narraban, algo que resultaba imposible de sistematizar; observó que el cuento atribuía frecuentemente las mismas acciones a personajes diferentes. Por lo tanto, asumió que el análisis debía partir de las funciones de los personajes, es decir, de la acción de un personaje y de su significado en el desarrollo de la intriga. Comprobó que en los cuentos del folclore las funciones son constantes, limitadas y en sucesión idéntica. Finalmente, propuso la definición de cuento maravilloso como aquél en el que se da un "desarrollo narrativo que parte de un daño o de una carencia y pasa por funciones intermedias para concluir en un casamiento o en otras funciones utilizadas como desenlace. La función terminal puede ser la recompensa, el apoderamiento del objeto de las búsquedas, la reparación del daño..." ${ }^{42}$.

En el Juego de la Oca podemos constatar muchas de estas funciones; la novedad es que los personajes son los propios jugadores. En efecto, estas funciones son fácilmente transportables a las estaciones que conforman el laberinto que acoge al juego. Junto a ellas, los intervalos numéricos y el simbolismo de las cifras terminan de conformar el entorno en el que habrán de desarrollarse el juego y las aventuras. Imaginemos, pues, un intrincado tablero que recogiera las peripecias del héroe Odiseo tras la toma de Troya. El mar es el elemento en el que trascurrirá el juego, un espacio laberíntico donde los caminos se confunden. Sentados ante el tablero, repasemos las funciones de Propp y comprobemos cómo fichas y casillas adquieren poco a poco la personalidad de los personajes de la Odisea; podremos ver en el juego la reproducción del mismo relato que Homero ha sublimado en su poema. El conjunto está a la vista de los jugadores, las sesenta y tres casillas reflejan todas las vicisitudes y posibles desarrollos del juego al modo que la rememoración de Odiseo en la isla de los feacios trae ante el auditorio el relato de los acontecimientos.

La premisa inicial obliga al héroe-jugador a iniciar el regreso-partida; esta sería la primera función de la nomenclatura de Propp: "uno de los miembros de la casa se aleja" (una vez supuesta la salida de Ítaca, es la partida de Troya tras el enfrentamiento con Poseidón la que inicia la aventura). Los textos clásicos dan cumplida información de los largos años que ha necesitado el asalto final a la ciudad de Príamo y del regreso funesto que se cobró la vida de buena parte de las fuerzas sitiadoras. Odiseo transgrede un mandato primordial, ciega al cíclope Polifemo, hijo de Poseidón; desde entonces navega sometido a pruebas y sinsabores que le llevarán a la redención a través de este mismo peregrinaje. Una a una se van cubriendo las casillas de un juego en el que el azar es la única oportunidad para la liberación. Situada la ficha del héroe en el tablero, disponemos las esferas de actuación del resto de personajes que participarán en este lance. Odiseo, en su deambular, contará con la enemistad manifiesta del antagonista Poseidón y la ayuda inestimable de Atenea y varias mujeres donantes, en términos de Propp.

La partida tiene las reglas establecidas: Odiseo debe emprender el regreso desde Troya hasta Ítaca donde le aguarda su fiel esposa Penélope, pero no es la única protagonista femenina, ni mucho menos. En realidad, podría decirse que el mismo viaje parece un itinerario cuyas estaciones son las mujeres, divinas o mortales, así como el lance del jugador está aliviado por la compañía de las ocas. Ellas lo impulsan hacia su siguiente destino, la oca madre o la oca esposa. También es curioso que Homero preste

42 V. Propp, Morfología del cuento, p. 121. 
más atención a cualquiera de ellas que a la propia Penélope ${ }^{43}$ que, con un carácter a veces contradictorio, hace dudar sobre sus intenciones.

Iniciada la jugada, son los números y su simbolismo los que atraen la atención, tanto en la Odisea como en el Juego de la Oca. Cassirer señala al hablar del número su dimensión mítica:

Siempre que dos cantidades aparecen como iguales en número, es decir, cuando resulta que pueden ser coordinadas entre sí miembro a miembro, el mito "explica" esta posibilidad de coordinación, que en el conocimiento aparece como una relación puramente ideal, atribuyendo una misma "naturaleza mitológica" común a las dos cantidades... Mientras que para el pensamiento lógico el número posee una función universal, una significación universal válida, para el pensamiento mitológico aparece enteramente como una "entidad" originaria y comunica su esencia y su poder a todo aquello sometido a él ${ }^{44}$.

El primer paralelismo entre el relato de la Odisea y el Juego de la Oca es claro: siete figuras de mujer coadyuvan en el final feliz de la partida. Siete personajes que encarnan variados papeles, desde el más relevante de Atenea hasta las actuaciones auxiliares de Circe, Calipso, Ino Leucótea, Nausícaa, Arete y Euriclea; todas sus intervenciones confluyen en el encuentro final con Penélope. Siete mujeres, como siete eran los sabios de Grecia o los reyes de Roma, siete las maravillas del mundo antiguo y siete los que fueron contra Tebas; siete los cuerpos celestes de la Antigüedad y los días de la semana ${ }^{45}$; y también los colores del arco iris. Esta repetición del siete convierte a este número en el símbolo del ciclo completo y la perfección.

Añadamos a esto que el tablero contiene catorce ocas, siete duplicado, que alivian la partida al jugador (como catorce era el número de efebos y doncellas elegidos para ser sacrificados al Minotauro en el laberinto; y catorce las estaciones del via crucis, una sustanciación religiosa de este peregrinar reparador, primigenio y politeísta) ${ }^{46}$; ellas impulsan al jugador hacia su siguiente destino, como el retorno de Odiseo está propiciado por la actuación de las figuras femeninas.

Las ocas aparecen dispuestas en secuencias de cuatro y cinco casillas sobre el tablero, una sucesión simbólica que conjuga el cuadrado (que figura lo racional sobre la tierra, la cruz de los puntos cardinales y el ciclo de las estaciones) con la quintaesencia de la unión representada por el cinco (que suma los principios de la vida encarnados por el cielo y la tierra, Urano y Gea). Nueve también es el número de pruebas u obstáculos que hay que afrontar en el juego (puente; posada; primeros dados; pozo; laberinto; cárcel; segundos dados; muerte y puerta del jardín). Encontramos una oca, así, en todas las casillas múltiples de nueve. Si nueve es la pauta entre cada pareja de ocas, también son nueve los años que permanecerá Odiseo con Calipo, auxiliar femenino que con su actuación favorece al héroe a través de su peregrinar en la búsqueda de un

43 Penélope es un nombre parlante cuyo significado es "la que pela o deshila" (cf. $\lambda \dot{\pi} \pi \omega$ ) la trama de un tejido ( $\pi \eta ́ \vee \eta, \pi \eta v i ́ o v)$, en alusión al ardid con el que demoraba la respuesta a los pretendientes (Od. 2.104 ss). Es curioso constatar que de ella tomó el nombre una raza de patos, Anas penelope, el silbón europeo, conocida por la fidelidad de las parejas.

44 Cassirer (1972), pp. 183-4.

45 Cf. Cassirer (1972), p. 191.

46 Sobre el simbolismo del siete en la dimensión mítica (septenarius numerus est perfectionis), cf. Cassirer (1972), pp. 186-187; 190-191. 
matrimonio renovado. Nueve días suele ser también la duración de las navegaciones, como la que lleva al laertíada de la isla Eolia hasta las inmediaciones de Ítaca; o el naufragio que lo arrastra desde el torbellino de Caribdis a la acogedora Ogigia.

\section{El cuento en el Juego de la Oca}

El esquema agencial de Propp se rastrea tanto en el poema homérico como en el desarrollo del juego. Cometida la transgresión inicial, se inicia la partida en la que tanto el jugador como el héroe tienen como meta la casilla 63, situada en la isla de Ítaca (final y principio) en la que aguarda la gran oca encarnada en Penélope, la función final que da sentido al conjunto. La suerte decidirá las etapas que el jugador deberá cubrir y que el héroe completará en su integridad. Destaquemos algunas de las funciones que describe Propp y que tienen cumplida presencia en el tablero y en el devenir de la Odisea.

En la función XXII, "el héroe es auxiliado" se distingue la subfunción: "el héroe vuelve a partir, vuelve a emprender una búsqueda"; ambas están representadas en el juego a través de la posibilidad de empezar de nuevo cada vez que se da un paso atrás: ocas, puente, dados y, sobre todo, laberinto.

También el héroe se ve obligado a enfrentar algunos episodios sin apenas relevancia; cícones y lotófagos son como aquellas celdillas que ilustran los recorridos de tantos como variados tableros del Juego de la Oca podamos contemplar. La casilla 6 representa la corriente de un río que atraviesa los ojos de un puente y llevará al jugador hasta la casilla 12, o viceversa, pues la suerte no siempre es aliada del jugador. Del mismo modo, las aventuras iniciales parecen favorecer los intereses de Odiseo y sus compañeros que surcan los mares no sin algún que otro disgusto, como el terrible encuentro con los lestrígones devoradores de hombres.

Otra de las funciones estructuralistas, la XII, afirma que "el héroe sufre una prueba, un cuestionario, un ataque que le preparan para la recepción de un objeto o de un auxiliar mágico". En ocasiones el juego depara sorpresas inesperadas; también los protagonistas de los cuentos reciben la ayuda en forma de objeto mágico de un donante. Por ejemplo, la entrega por parte de Hermes a Odiseo de una hierba, $\mu \tilde{\omega} \lambda v$, como antídoto para los hechizos de Circe. A pesar de estas ayudas, una actuación errónea devuelve a los protagonistas al peligro al no superar la prueba requerida; $y$, desandado el camino, ha de volver a empezar: Odiseo arriba a la isla de Eolo, el señor de los vientos. El aire es un poder renovador, capaz de fecundar y originar la vida; pero su transformación en viento y tempestad puede causar estragos. Eolo domina todos los vientos y regala a Odiseo el odre que los contiene, salvo la brisa benéfica de Céfiro que debe conducirlo con sus compañeros hasta el final del recorrido; al odre le acompaña la advertencia de no abrirlo durante la singladura, algo que encaja perfectamente con la función II: "recae sobre el protagonista una prohibición". Pero la avaricia no conoce límites; tal y como sucede en otros juegos de dados en los que la repetición de la máxima cifra es una condena a reiniciar la partida, los compañeros sospechan del contenido real del odre y al abrirlo, confiados en descubrir un preciado tesoro, desatan la fuerza incontrolable de los vientos y, al igual que el jugador que se detiene en la casilla 12 se ve arrastrado por una corriente inversa de nuevo a la casilla 6 , deshacen el camino recorrido y regresan junto al divino Eolo que ya no los acoge de buen grado ${ }^{47}$.

47 A la función II le sigue la función III, "la prohibición se transgrede”, con sus consecuencias. 
Existen otras figuras auxiliares que ayudan al participante a lo largo del juego: más adelante, el héroe se encontrará con otros donantes, los feacios ${ }^{48}$. Estos, como los dados de la casilla 26, proporcionan un impulso final, sin vuelta atrás y casi decisivo hasta Ítaca o la casilla 53; es cierto que no garantizan la victoria porque aún restan peligros que salvar, pero el desenlace está ya próximo.

En el juego, los peligros, productos de azar, son equivalentes a las prohibiciones. La suerte presenta al jugador variados peligros, sobre todo en los turnos que lo acercan al deseado final y cuya repercusión en el lance es progresiva: la posada detiene brevemente la ficha, el pozo requiere de la intervención de otro jugador para superarlo, en la cárcel se debe permanecer hasta tres manos y, por último, no eludir la casilla 58, ilustrado con algún símbolo mortal, devuelve al jugador a la casilla de salida, alejándolo casi definitivamente de cualquier posibilidad de triunfo. También el héroe del cuento maravilloso se ve sometido a numerosas pruebas antes de alcanzar el reconocimiento y la recompensa final. Es cierto que su proceloso navegar le depara dulces peligros que lo mantienen alejado del mar en amorosas estancias: Calipso goza de su compañía nueve años y Circe, que también es un actante decisivo en el futuro del héroe, comparte su lecho durante un largo año. Pero no todos los obstáculos son tan amables: Odiseo desciende al Hades y tiene que lograr volver a la luz de los vivos tras obtener de Tiresias la información anhelada ${ }^{49}$; no debe volver a transgredir las prohibiciones que los dioses han marcado (aunque sus compañeros devoren con insensato sacrilegio las vacas de Helio apacentadas en la isla de Trinacria). Conforme consume el tiempo de sus aventuras, los peligros son mayores; los episodios señalados son pasajeros y no definitivos hasta que planta cara a los dos últimos: el embaucador canto de las sirenas y el escabroso estrecho que acoge a las terribles Escila y Caribdis. En el tablero, la casilla 42, que representa la esencia laberíntica, devuelve sin contemplaciones a la celda número 30. Por su parte, la pareja de monstruos encarna el poder funesto de la espiral que decrece hacia su interior: la primera asume la espantosa apariencia de una serpiente de múltiples cabezas; mientras que Caribdis es la sustanciación en una vorágine que amenaza con abismar en el horror al náufrago.

Propp define así la función XXV: "se propone al héroe una tarea difícil"; sortear las sirenas y pasar junto a la casilla 58 son empresas de este calado. El paralelismo visual es evidente: la muerte, representada tradicionalmente por una calavera sobre un aspa de huesos, tiene su reflejo en la descripción de los arrecifes de la isla que habitan estas aves con busto de mujer, cubiertos con los restos de los que escuchan con atención sus cantos. Las sirenas son un ser híbrido, mediador entre el mar y la tierra y también entre el cielo y la tierra; y entre la vida y la muerte. Su poder es la atracción y la seducción, que obtienen mediante su canto. El peligro que suponen puede traducirse en un quebranto de la travesía, en una pérdida del regreso al hogar. En cierto sentido, tiene un parecido con los seductores peligros de la isla de los lotófagos: el olvido supone también el final del viaje. Por ello, mediante la seducción, truncan el viaje y substraen la fuente de conocimientos que en Homero es más motivo de tentación que el erótico. Así cantan las sirenas a Odiseo:

\footnotetext{
48 Su actuación corresponde con la función XV: "el héroe es transportado, conducido o llevado cerca del lugar donde se halla el objeto de su búsqueda".

49 Ahora es la función IV: "el agresor intenta obtener noticias", sin equivalente en el Juego de la Oca.
} 
¡Ven, acércate, muy famoso Odiseo, gran gloria de los aqueos! ¡Detén tu navío para escuchar nuestra voz! Pues jamás pasó de largo por aquí nadie en su negra nave sin escuchar la voz de dulce encanto de nuestras bocas. Sino que ése, deleitándose, navega luego más sabio ${ }^{50}$.

Así le había advertido anteriormente Circe al describir la isla:

Llegarás junto a las Sirenas, las que hechizan a todos los humanos que se aproximan a ellas. Cualquiera que en su ignorancia se les acerca y escucha su voz, a ése no le abrazarán de nuevo su mujer ni sus hijos contentos de su regreso a casa. Allí las Sirenas lo hechizan con su canto fascinante, situadas en una pradera. En torno a ellas amarillea un enorme montón de huesos y renegridos pellejos humanos putrefactos $^{51}$.

Al contar a sus compañeros lo que le ha revelado Circe, la alternativa es clara: "muramos o tomemos precauciones para rehuir la muerte y el destino" 52 . Por ello, Odiseo ha de usar su astucia para salvaguardarse a sí mismo, no como los ingenuos marineros a los que el azar lleva al final del viaje de la vida. El dilema que se plantea Odiseo es entre la vida y la muerte, la imposibilidad de su retorno a la patria. Pero en el Juego de la Oca, la evasión de este peligro depende de nuevo de la suerte. Al igual que Odiseo sortea los hechizos mágicos femeninos, una oca anterior puede ayudar al jugador a sobrepasar la fatídica casilla 58, hasta la siguiente, una oca salvadora: el final del trayecto.

El final del relato coincide con la función XXXI: “el héroe se casa y asciende al trono", simbolizado por el retorno al hogar y el reencuentro con Penélope. Pero son los otros personajes femeninos, como ya se ha indicado anteriormente, los que desempeñan papeles determinantes en el transcurso de la narración. Todas las mujeres de la Odisea juntas muestran una alternativa a ese matrimonio renovado en un conjunto de variada personalidad. Calipso, amante ardiente pero divina, ofrece la inmortalidad al héroe a cambio de amor y de llenar su soledad infinita. Circe, maga y poderosa, se ofrece a sí misma tras ser vencida por su astucia y le proporciona las claves para salvar los seguros peligros que afrontará en el mar. Un personaje intermedio entre la ardiente Calipso y la consejera Circe es la princesa Nausícaa, enamorada con ingenuidad infantil del extranjero apenas lo descubre náufrago en la playa; su madre Arete, la más insigne de los ciudadanos de Feacia, prevalece en un mundo de varones y otorga hospitalidad a Odiseo. Participan también de estas acciones coadyuvantes dos personajes fugaces, Ino Leucótea y Euriclea; la primera una divinidad que garantiza la salvadora llegada a la isla de Esqueria; la leal sirviente es el personaje con más fuerza en el palacio tomado por los arrogantes pretendientes, y el que compensa las indefiniciones de su ama Penélope ${ }^{53}$. Por último, Atenea procura ayuda y aliento a Odiseo y a cuantos puedan socorrerlo en su regreso. La intimidad entre la diosa y el héroe es tan nueva y estrecha que, si no fuera por el carácter virginal de la deidad y el afán censor de Homero, se podría sospechar que es el amor lo que la impulsa a protegerlo.

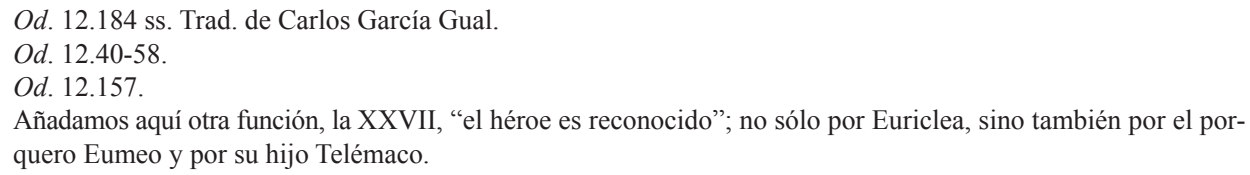




\section{Conclusión}

Las fuentes griegas nos permiten deducir que ya en la Antigüedad griega existía la estructura de un juego de mesa que combinaba azar y una carrera; también nos confirman que la invención mítica corresponde a Palamedes.

En el Juego de la Oca, tal como lo conocemos actualmente, se vislumbra un universal que comparte con la Odisea y los cuentos populares: un símbolo de la vida convertida en un viaje laberíntico al punto de partida, al origen; un viaje propio de Odiseo y que se revive en las vicisitudes de cada jugador y conforme a los motivos del cuento tradicional.

\section{Obras citadas}

Arnott, W.G. Birds in the Ancient World, Londres, 2007.

Attali, J. Chemins de sagesse (traité du labyrinthe) s. 1. 1966.

Baratte, F. "Le mosaïque de Fortuna Redux à Tebassa", Bulletin de la Societé National des antiquaires de France, 1973.

Cassirer, E. Antropología filosófica. Introducción a una filosofía de la cultura. Méjico, 1945.

- Filosofía de las formas simbólicas, II. El pensamiento mítico. México, 1972.

Daremberg, C. et alii. Dictionaire des antiquités grecques et romaines. París, 1969.

Dunbabin, K.M.D. The mosaics of roman North Africa. Oxford,1978.

Huizinga, J. Homo ludens. Madrid, 2012.

Ibáñez Noguerón, C. Aproximación al laberinto. Granada, 2010.

Kurke, L. "Ancient Greek Board Games and How to Play Them", Classical Philology 94 (1999) 247-267.

López Poza, S. "Expresiones alegóricas del hombre como peregrino en la tierra", De oca a oca... polo Camiño de Santiago. Santiago de Compostela, 2004.

Martínez Vázquez de Parga, M.J. El tablero de la oca: Juego, figuración, símbolo. Madrid, 2008.

Méndez Filesi, M. El laberinto. Historia y mito. Barcelona, 2009.

Poirier, R. Iconographie des jeux de L'oie (1638-1950). París, 1950.

Propp, V. Morfología del cuento. Madrid 1985.

Ruipérez, M.S. y Melena, J.L. Los griegos micénicos. Madrid, 1990.

Santarcangeli, P. El libro de los laberintos: Historia de un mito y de un símbolo. Madrid, 1997. 